Case Report

\title{
Brain Abscess in Undiagnosed Tetralogy of Fallot
}

\author{
Kelvin Nemayire $^{1,}$ *, Kantenga Dieu Merci Kabulo ${ }^{1}$, Luxwell Jokonya ${ }^{1}$, Patrice Ntenga ${ }^{2}$, \\ Aaron Masiiwe Musara ${ }^{1}$, Kazadi Kaluile Ntenga Kalangu ${ }^{1}$ \\ ${ }^{1}$ Department of Neurosurgery, University of Zimbabwe, Harare, Zimbabwe \\ ${ }^{2}$ Neurological Clinic of the National Teaching Hospital-Fann, Dakar, Senegal
}

Email address:

tikenema7@gmail.com (K. Nemayire)

${ }^{*}$ Corresponding author

\section{To cite this article:}

Kelvin Nemayire, Kantenga Dieu Merci Kabulo, Luxwell Jokonya, Patrice Ntenga, Aaron Masiiwe Musara, Kazadi Kaluile Ntenga Kalangu. Brain Abscess in Undiagnosed Tetralogy of Fallot. International Journal of Immunology. Vol. 6, No. 1, 2018, pp. 1-4.

doi: $10.11648 /$ j.iji.20180601.11

Received: September 5, 2017; Accepted: January 3, 2018; Published: January 19, 2018

\begin{abstract}
Cardiovascular disease is a leading cause of mortality in all ages worldwide. Tetralogy of Fallot (TOF) is the most common cyanotic congenital heart disease (CHD) accounting for $10 \%$. There have been several reports of neurological complications associated with TOF. Although it is known, brain abscess (BA) is a serious complication in patients with uncorrected CHD mostly in the age of 4-7 years-old. We report a case of a 7 year old male who presented with a 3 month history of left sided body weakness and a 3 week history of a headache and fever. Patient was chronically unwell since birth where he would experience occasional episodes of exertional dyspnoea which was never investigated. Chest xray showed a globular-shaped heart. CT scan brain showed a $1,8 \times 1,3 \times 1,5 \mathrm{~cm}$ ring-enhancing lesion in the right parietal region with minimal perilesional vasogenic edema communicating with the body of the lateral ventricle, with enhancement of the ependymal lining of the ventricle; echocardiography revealed ventricular septal defect (VSD), overriding of aorta, obstruction to right ventricular outflow tract and hypertrophy of right ventricle consistent with a diagnosis of TOF. We elected to manage the patient conservatively on intravenous antibiotics, Patient improved significantly neurologically and was transferred to the cardiothoracic surgeons for further management of TOF.
\end{abstract}

Keywords: Brain Abscess, Tetralogy of Fallot, Cyanotic Congestive Heart Disease, Exertional Dyspnoea

\section{Introduction}

Cardiovascular disease is a leading cause of mortality in all ages worldwide [1, 2]. Tetralogy of Fallot (TOF) is the most common cyanotic congenital heart disease (CHD) accounting for $10 \%$. The TOF is characterized by ventricular septal defect, overriding aorta, hypertrophy of right ventricle and right ventricular outflow tract obstruction (RVOT) which can be valvular, infundibular or both [3, 4]. Tetralogy of Fallot (TOF) is a leading cause of cyanotic congenital heart disease and forms about $10 \%$ of total congenital heart diseases and constitutes $13-70 \%$ of all brain abscess $[5,6]$.

\section{Case Presentation}

A 7 year old male who presented with a 3 month history of left sided body weakness and a 3 week history of a headache and fever. There was no history of trauma. Patient was chronically unwell since birth where he would experience occasional episodes of exertional dyspnoea which were never investigated. His mother noted that he had a smaller body size as compared to children of his age. He attained all his developmental milestones on time. 3 months prior to presentation he developed weakness of the left upper limb which was followed by weakness of the left lower limb. Symptoms progressed until he could no longer mobilize. three weeks prior to presentation he then started complaining of a severe global headache which was associated with none projectile vomiting but there were no seizures. At the same time he developed a fever with temperature of $38,7^{\circ} \mathrm{C}$. No family history of malignancies or congenital malformations. Patient was admitted at a local hospital where a lumbar puncture was done which showed about 2000 white cells 
predominantly polymorphonuclear leucocytes, turbid colour, a glucose of $2,1 \mathrm{mmol} / \mathrm{l}$ and a slightly elevated protein with which he was subsequently started on intravenous antibiotics for a bacterial meningitis.

Patient started showing signs of deterioration while at the local Hospital which prompted a referral to our emergency department. Patient was initially admitted by paediatricians who ordered a CT scan of the brain after which they consulted Neurosurgeons.

On examination, he was an ill looking patient in mild respiratory distress as evidenced by use of accessory muscles of respiration, had grade 4 clubbing. His level of consciousness was $15 / 15$, pupils were $4 \mathrm{~mm}$ bilaterally, regular and reactive to both light and accommodation. There was left sided hemiparesis, hypertonia, hyperreflexia and had a positive Babinski sign and clonus.

Chest examination revealed a murmur but examination of all the other systems was normal.

Complete blood count showed an MCV of 56,5, haemoglobin of $11 \mathrm{gd} / 1$, PLT of 180 . Urea and electrolytes showed a mild hyponatremia of $128 \mathrm{mmol} / 1$, potassium of $4,7 \mathrm{mmol} / 1$, Urea of $5,8 \mathrm{mmol} / 1$ and a creatinine of 114 . No organism was isolated from blood culture samples.

Chest X-ray showed a globular-shaped heart.

CT scan brain showed a 1, $8 \times 1,3 \times 1,5 \mathrm{~cm}$ ring-enhancing lesion in the right parietal region with minimal perilessional vasogenic edema communicating with the body of the lateral ventricle. The ventricles were moderately dilated and showed increased enhancement of the ependymal lining with appearances consistent with a communicating hydrocephalus with ventriculitis. Patient was investigated for the exertional dyspnoea with echocardiography which revealed ventricular septal defect (VSD), overriding of aorta, obstruction to right ventricular outflow tract and hypertrophy of right ventricle consistent with a diagnosis of TOF.

We elected to manage the patient conservatively on intravenous antibiotics ceftriaxone and metronidazole for 6 weeks then followed by oral antibiotics for a further 6 weeks since the size was small and it was deep seated and the fact that it had already ruptured into the ventricle and also the newly diagnosed and uncorrected TOF. Patient improved significantly neurologically and was transferred to the cardiothoracic surgeons.

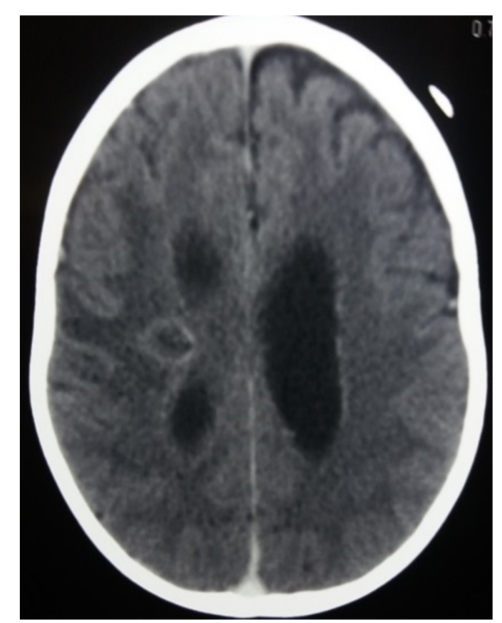

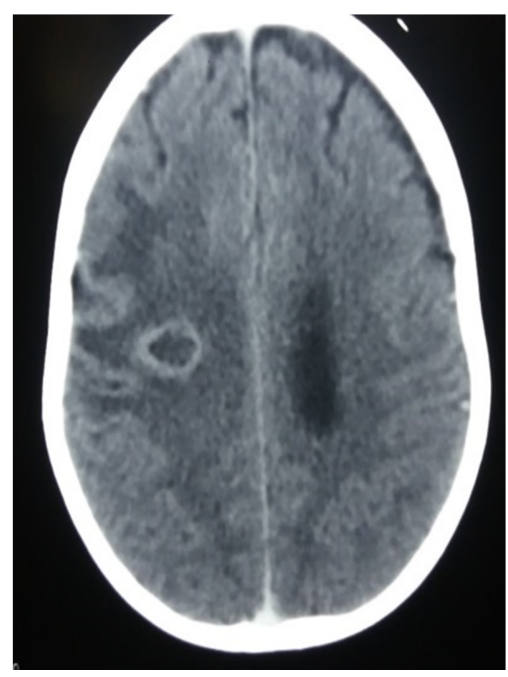

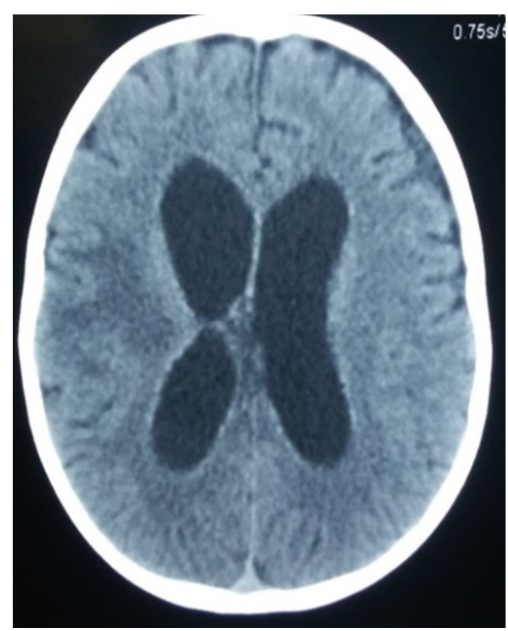

Figure 1. CT scan brain showing a 1,8 $\times 1,3 \times 1,5 \mathrm{~cm}$ ring-enhancing lesion in the right parietal region with minimal perilessional vasogenic edema communicating with the body of the lateral ventricle. The ventricles are moderately dilated and showed increased enhancement of the ependymal lining with appearances consistent with a communicating hydrocephalus with ventriculitis.

\section{Discussion}

The incidence of brain abscesses is $\sim 8 \%$ of intracranial masses in developing countries, whereas in the West the incidence is $\sim 1-2 \%[7,8]$.

Children with TOF are susceptible to serious neurological complications like cerebrovascular accidents (stroke) and brain abscess, which are mainly responsible for mortality and morbidity in these patients $[9,10]$.

Brain abscess and cerebrovascular accidents are common neurological complications in unoperated children with Tetralogy of Fallot which are responsible for mortality and morbidity in them. Frequency of brain abscess is found to be more than cerebrovascular accidents in these patients [11].

Patients with cCHD (cyanotic congestive heart disease) develop repeated brain abscesses secondary to polycythemia-induced cerebral infarcts; further, poor host immunity and bypass of lung phagocytosis are contributory factors. cCHD, especially Tetrology of Fallot (TOF), accounts 
for nearly $13-70 \%$ of all brain abscess cases [12].

Patients with cCHD suffer from the ill-effects of chronic hypoxemia; this usually manifests as persistent breathlessness and tiredness, repeated chest infections and fever, growth retardation, delayed milestones, severe metabolic derangements, multi-organ failure, and major neurological deficits secondary to a vascular stroke or brain abscess. A deficiency of vitamin $\mathrm{K}$-dependent clotting factors, decreased and defective platelets, and accelerated fibrinolysis results in abnormal hemostasis with frequent and increased bleeding; the presence of CCF, arrhythmias, heart blocks, and infective endocarditis can cause severe hemodynamic instability. cCHD patients also have recurring bouts of severe cyanosis and hypoxemia, known as cyanotic spells, which can lead to convulsions, syncope, stroke, and death; spells are triggered by a heightened sympathetic activity during crying, agitation, or fright and results in increased right-to-left shunting [13].

Regarding antibiotic therapy for the past 20 years high dose intravenous penicillin $\mathrm{G}$ and chloramphenicol have been used to treat brain abscess in this setting with satisfactory outcomes [14].

Actually, metronidazole is usually combined with third generation cephalosporins or penicillin $\mathrm{G}$ for the treatment of the patients with cyanotic heart disease complicated with BA [14]. The third generation cephalosporins are much more expensive than penicillin $G$ there is a need to evaluate their effects [15].

In our case we used metronidazole and ceftriaxone. With regards to surgery, brain abscess may be removed through osteoplastic craniotomy with removal of abscess capsule, or the abscesses may be treated by aspiration and drainage of the abscess under stereotaxic guidance. This procedure can be made by general or scalp block anesthesia with good result, but require expensive apparatus and expertise [16].

For the anesthetic management of these patients, one should be careful about the drugs and events that may increase the R-L shunt [17].

The severity of the disease directly correlates with the size of VSD, severity of pulmonary stenosis and functional status of the right ventricle [18].

Complications of right to left shunts include chronic hypoxia leading to pulmonary vasoconstriction, altered acid base status, polycythemia, coagulopathy, infective endocarditis and cerebral abscess due to increased risk of paradoxical emboli.

Anesthetic management of these patients is always a challenge for the anesthetists because of the cardiopulmonary and coagulation abnormalities, dehydration and electrolyte imbalance, along with abscess-induced complications of seizures, meningitis and raised intracranial pressure [19].

General anesthesia with controlled ventilation has the advantage of better oxygenation but can be associated with the risk of hemodynamic instability, along with compression of pulmonary vessels, impaired gas exchange and academia [20, 17].

In our case we opted to treat the patient conservatively since the abscess was less than $2 \mathrm{~cm}$ in diameter and it was deep seated and had already ruptured into the ventricle although neurologically the patient was not exhibiting any signs of deterioration, The other reason why we elected for conservative treatment was that there were anaesthetic risks associated with an uncorrected TOF and using the above approach our patient improved well.

\section{Conclusion}

Brain abscesses in patients with TOF are common. Treatment of patients with newly diagnosed and uncorrected TOF with small abscesses, sizes less than $3 \mathrm{~cm}$ in diameter, deep seated and those in eloquent areas, especially in patients with stable neurological condition can be treated conservatively with intravenous antibiotics with fairly satisfactory results.

\section{References}

[1] Hoffman JIE (2002) Incidence, mortality, and natural history. In: Anderson RA, Macartney F, Shinebourne EA, Tynan M, editors. Paediatric Cardiology. London: Churchill Livingstone $111-40$.

[2] Santulli G (2013) Epidemiology of Cardiovascular Disease in the 21 st Century: Updated Numbers and Updated Facts. JCvD 1: $1-2$.

[3] Sethi S, Kapil S (2014) Scalp block for brain abscess drainage in a patient with uncorrected tetralogy of Fallot. WJCC 2: 934-937.

[4] Manuel V, Matias E, Morais H, Miguel G, Nunes MA, de Oliveira A, Manresa J, Junior AP. Brain Abscess in Uncorrected Tetralogy of Fallot Diagnosed during Preparation for Computed Cardiac Angiotomography. J Cardiovasc Dis Diagn. 2015; 3: 193. doi: 10.4172 / 2329-9517.1000193.

[5] Sidharth Sraban Routray, Khageswar Raut, Debasis Mishra and Rajib Mishra, Cerebral Abscess in a 8 years old with uncorrected tetralogy of Fallot: Anaesthetic challenge, ISSN: 2229-3809 (Online) Journal DOI:10.7439/ijbar, IJBAR (2013) 04 (11).

[6] Ghafoor T, Amin MU. Multiple brain abscesses in a child with congenital cyanotic heart disease. J Pak Med Assoc. 2006; 56: 603-5.].

[7] Bernardini GL: Diagnosis and management of brain abscess and Subdural empyema. Curr Neurol Neurosci Rep 4: 448-456, 2004.

[8] ranjith k. moorthy, m. ch., and vedantam rajshekhar, m. ch., Management of brain abscess: an overview, Neurosurg Focus 24 (6): E3, 2008.

[9] (Bermstein D. Congenital heart disease. In: Kleigman MR, Behrman ER, Janson BH, Stanton FB. Nelson textbook of pediatrics. 18th ed. New Delhi: Elsevier; 2008. p. 1906-11.

[10] Sadiq A, Shymkrishnan GK, Theodore S, Gopalkarishnan S, Tharakan MJ, Karunkaran J. Long term functional assessment after correction of tetralogy of fallot in adulthood. Ann Thorac Surg 2007; 83: 1790-5.). 
[11] Sommayya aftab, amir usman, tipu sultan, frequency of cerebrovascular accidents and brain abscess in childrens with tetralogy of fallot, pakistan journal of neurological sciences, vol. 10 (2) apr - jun 2015.

[12] Ghafoor T, Amin MU. Multiple brain abscesses in a child with congenital cyanotic heart disease. J Pak Med Assoc. 2006; 56: 603-5. [PubMed] 2. Prusty GK. Brain abscesses in cyanotic heart disease. Indian J Pediatr. 1993; 60: 43-51. [PubMed].

[13] Abhijeet Raha, Pragati Ganjoo, Amay Singh, Monica S. Tandon, and Daljit Singh, Surgery for brain abscess in children with cyanotic heart disease: An anesthetic challenge, J Pediatr Neurosci. 2012 Jan-Apr; 7 (1): 23-26.

[14] Lumbiganon P, Chaikitpinyo A (2013) Antibiotics for brain abscesses in people with cyanotic congenital heart disease. Cochrane Database Syst Rev 3: 1-13.

[15] Sani MU, Mukhtar-Yola M, Karaye KM (2007) Spectrum of congenital heart disease in a tropical environment: an echocardiography study. J Natl Med Assoc 99: 665-669.
[16] Sethi S, Kapil S (2014) Scalp block for brain abscess drainage in a patient with uncorrected tetralogy of Fallot. WJCC 2: 934-937.

[17] Sethi S, Kapil S. Scalp block for brain abscess drainage in a patient with uncorrected tetralogy of Fallot. World J Clin Cases2014; 2 (12): 934-937.

[18] Webb GD, Smallhorn JF, Therrien J, Redington AN. Congenital heart disease. In: Zipes DP, Libby P, Bonow RO, Braunwald E, editors. Braunwald's heart disease: a textbook of cardiovascular medicine. 7th ed. Philadelphia: W. B. Saunders, 2005: 1489-1552.

[19] Raha A, Ganjoo P, Singh A, Tandon MS, Singh D. Surgery for brain abscess in children with cyanotic heart disease: An anesthetic challenge. J Pediatr Neurosci2012; 7: 23-26 [PMID: 22837772 DOI: $10.4103 / 1817-1745.97617$.

[20] Ahmed I. Tetrology of Fallot and pregnancy. RMJ2004; 29: 76-79. 